\title{
Coming Full Circle: White, Euro-Canadian Teachers’ Positioning, Understanding, Doing, Honouring, and Knowing in School-Based Aboriginal Education
}

\author{
Brooke Madden
}

\author{
University of British Columbia
}

\begin{abstract}
This narrative study contributes to the field of school-based Indigenous education by exploring the central research question: What are the decolonizing processes of practicing teachers involved in a provincially funded initiative to improve schooling for urban Aboriginal students? Excerpts from teachers' narratives are organized using the Anishinaabe medicine wheel, anchoring the exploration of the following five directions and associated decolonizing processes: teachings from the centre/positioning, teachings from the east/honouring, teachings from the south/understanding, teachings from the west/doing, and teachings from the north/knowing. This paper concludes with a discussion of how White, Euro-Canadian teachers' decolonization informs the fields of Indigenous education, teacher education, and narrative inquiry.
\end{abstract}

Keywords: decolonization; processes; teacher practices; Indigenous education; teacher education; narrative inquiry

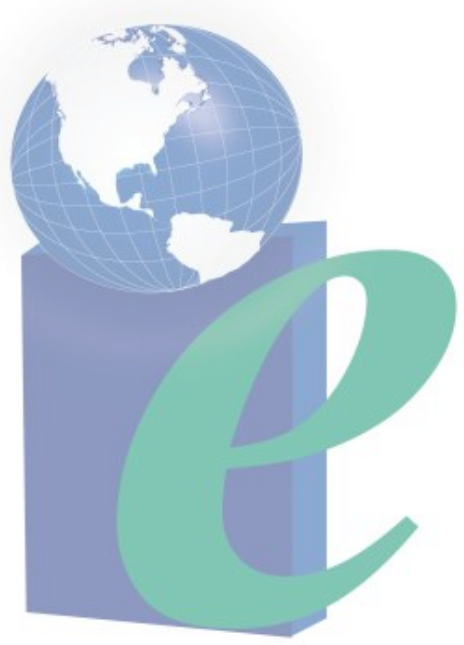




\section{Coming Full Circle: White, Euro-Canadian Teachers' Positioning, Understanding, Doing, Honouring, and Knowing in School-Based Aboriginal Education}

The vast majority of research on Indigenous ${ }^{1}$ education continues to focus on university contexts (e.g., Phillips \& Whatman, 2007; Sanford, Williams, Hopper, \& McGregor, 2012; Wolf, 2012) and often reflects perspectives of teacher candidates (e.g., Dion, 2007; Tanaka et al., 2007; Tupper, 2011) and teacher educators (e.g., Belczewski, 2009; den Heyer, 2010; Iseke-Barnes, 2008; Oberg, Blades, \& Thom, 2007). While these studies have made significant contributions to understanding the principles, possibilities, and problems in preparing prospective teachers who accommodate and support the educational needs of Indigenous students and their communities, much less is known about practicing teachers' engagement in Indigenous education (for exception see Bishop, Berryman, Cavanaugh, \& Teddy, 2009; Dion, 2009; Strong-Wilson, 2007). This narrative study contributes to this lesser-known field of school-based Indigenous education by exploring the decolonizing processes of seven non-Aboriginal teachers involved in a provincially funded initiative to improve schooling for urban Aboriginal students.

Drawing on and extending a geographically and culturally situated model for teaching First Nations students (Flett \& Gardner, 2009), teachers' journeys of learning from Indigenous knowledges are examined and presented using the Anishinaabe ${ }^{2}$ medicine wheel and the corresponding teachings of how it can be applied for nourishing the teaching spirit. Excerpts from teachers' narratives anchor the exploration of the following five directions and their associated decolonizing processes: centre/positioning, east/honouring, south/understanding, west/doing, and north/knowing. Teachings from the centre demonstrate the positioning of oneself in relation to ancestral heritage and Indigenous peoples and land. Teachings from the eastern direction exemplify how teachers are honouring Indigenous knowledges and their relationships with human, natural, and spiritual worlds through cultural protocols, ceremony, and ritualized actions. Teachings from the southern direction illuminate the process of coming to understand how colonization, Eurocentrism, racism, and Whiteness are entangled and shape the current education system in ways that marginalize Indigenous knowledges and peoples. Teachings from the western direction illustrate how teachers are integrating Indigenous knowledges in their classrooms through culturally responsive pedagogy and learning alongside local Indigenous knowledge holders. Teachings from the northern direction focus on how teachers are conceptualizing Indigenous knowledges and knowledge holders and the role of decolonization in creating space for, and giving legitimacy to, Indigenous ways of knowing, being, and doing.

A discussion of three important contributions to the fields of Indigenous education, teacher education, and narrative inquiry concludes the manuscript. Teachings from each direction that focus on practicing teachers' decolonizing processes inform considerations for school-based Indigenous education initiatives. Findings also point to the importance of attending to the role of race and racism in non-Indigenous teachers' engagement in various Indigenous education initiatives, as well as the potential for building theory to develop a more fulsome and nuanced account of non-Indigenous decolonization. I conclude by discussing what it might mean to extend narrative inquiry for use in school-based Indigenous education contexts, and towards decolonizing goals. 


\section{Teachings From the Centre: Researcher Positioning}

“In the Indigenous world, knowledge is about relationships.” (Little Bear, 2009)

I have been taught by many Indigenous teachers that one must always begin the process of learning by locating oneself within the ongoing relationships that shape one's life. University of British Columbia, Elder in Residence, Larry Grant explains that this relational positioning is a traditional protocol observed by many First Nations. This protocol is rooted in the notion that one can only speak from the position they occupy and that this position, and situated knowledge that results, is embedded in a sentient place and shaped by relationships with family, community, band, and nation (Elder Larry Grant, personal communication, October 23, 2011).

While learning about what I thought was my multi-generation maternal French/German and paternal British/Irish settlement history in the geographical areas we now refer to as Southern Ontario and Atlantic Canada, I discovered my Aboriginal ancestry throughout both lineages. As someone who, for the majority of my career, has identified as a White, Euro-Canadian settler, I have come to recognize that the relational position I engage necessarily differs from that which is modelled by Indigenous knowledge holders alongside whom I learn. I work to translate the shared teachings into my particular and complicated context in an effort to move beyond the simple listing of markers of identity and disconnected ancestral lineages, towards honouring the sources of Indigenous knowledge that have come to guide how I learn, teach, and live.

I was raised in Tecumseh, a small town east of Windsor, Ontario. The Town of Tecumseh derives its name from the Shawnee chief who is often cast as one of "the great defenders of Canada," overshadowing the chief's motivation for allying with the British in the War of 1812 in an attempt to take back his peoples' traditional territory in the Ohio Valley that had been seized by the American militia (Gregg, 2012). The Town of Tecumseh is located on the traditional territory of the Caldwell First Nation. This nation, sometimes referred to as a "landless band," received a land dispute settlement in 2010 for land promised but never bestowed over 200 years ago (AANDC, 2010). I suspect that the absence of a physical Aboriginal reserve, coupled with an education seemingly devoid of Indigenous knowledges, peoples, and perspectives, led me to conclude until late in my teenage years that I did not know any Indigenous people. Years later, after embarking on a journey of listening anew, I re/turn to the (mis)places of my ancestors - my/self - and take note of spectres ${ }^{3}$ of Indigeneity that weave in out and out of our stories. A Michif ${ }^{4}$ lullaby sung by my Mémé, ${ }^{5}$ an edited family history of the settlement of a since dissolved township, and an acknowledgement from the land that I am welcome home: these exceed the available theoretical frames and identity categories, constraining my ability to acknowledge all my relations. The binary oppositions Aboriginal/non-Aboriginal and Indigenous/settler do little to account for differently shared histories and locations. I wonder if, in attending my own learning spirit, I am responding to (the relationships of) my ancestors, acknowledging the presence of Indigeneity that is always, already guiding my becoming.

Perhaps my qualification as a science teacher is what brought me to a small town in Northern Ontario where a large population of Anishinaabe secondary students travel 
from their home communities to live and learn during the school year. In relation with that place and the peoples of that land, I came to acknowledge my explicit implication in, and resultant privilege from, the very same colonial systems that this article seeks to resist. A vastly different notion of education was presented that required intergeneration learning, attending to the learning spirit (Battiste, 2012a), and pedagogies steeped in protocols and experiential learning on the land. I made the decision to begin graduate studies on the same traditional territory with an interest in collaborating with practicing teachers to share experiences of what I have come to understand as Indigenous education. The roots of the research presented herein extend to these locations, connecting me to a network that nurtures, diverts, strangles, accelerates, and expands.

\section{Theoretical and Methodological Framings: Decolonization Through Narrative Inquiry}

As a graduate research assistant, I contributed to a 2-year study ${ }^{6}$ of a provincially funded, district-wide project to improve schooling for urban Aboriginal students. ${ }^{7}$ Several components supported this Aboriginal education initiative, including the formation of an Aboriginal steering committee, employment of Aboriginal support workers in schools, and resource development. However, the most significant funding allotment was directed towards elementary and secondary teacher professional development (PD). Comments made during voluntary teacher focus groups ${ }^{8}$ that followed these PD sessions suggested that a small subset of teachers were engaged in decolonization.

The Indigenous framework for decolonizing education on which I draw involves the "two-prong process" of deconstructing and reconstructing (Battiste, 2012a, 2012b). Deconstruction involves examining colonization and colonial strategies that continue to be utilized by settlers to exploit and justify what many, including myself, regard as the theft of Indigenous lands and resources (e.g., government policies such as the Indian Act and treaties; Eurocentric history taught in Canadian schools; and research on, and resulting misrepresentations of, Indigenous peoples). Reconstruction centres Indigenous epistemologies and ontologies in working towards localized education and research priorities as outlined by Indigenous communities.

Nine teachers from the larger research study were invited to participate in an independent qualitative graduate study of practicing teachers' decolonization, which utilized narrative and which was conducted over an 8-month period that followed the district-wide study (Madden, 2011). Seven teachers agreed to take part: three elementary teachers and four secondary teachers, six females and one male. An invitation to participate was extended to those whose comments suggested their involvement in deconstructing and/or reconstructing as described above. For example, five out of seven teachers from this subgroup commented that their experiences of teaching in remote Aboriginal communities provided opportunities to consider and expand their taken-forgranted notions of education and teacher. Further, daily interaction and collaboration with community members resulted in an examination of prejudices and misconceptions that were held about Aboriginal peoples in Canada, treaty agreements and their associated rights and responsibilities, and residential schools. Similarly, comments made by all teacher participants suggested they were differently collaborating with Aboriginal community members, support workers, and/or teachers to learn how to incorporate local 
Aboriginal perspectives and approaches to teaching and learning in their classrooms.

At the time of the research, all teacher participants identified as non-Indigenous or non-Aboriginal. It is important to note that it was not a strategic research decision to select for this subset. Rather, this reflects the demographic of teachers in the school board studied of which over 90\% identified as White and/or of European heritage (Higgins, Madden, \& Korteweg, 2013). While this factor continues the marginalization of the experiences of Aboriginal teachers and non-Aboriginal, teachers of colour, it also presents important insights about the spaces between and among Whiteness and Indigenous education. Further, it offers an opportunity to explore this unique Northern urban context and its associated systemic and social challenges.

Clandinin and Connelly (1988) define narrative as "the study of how humans make meaning of experience by endlessly telling and retelling stories about themselves that both reconfigure the past and create purpose in the future” (p. 24). They propose the use of narrative as a methodology for studying and shaping teacher identity and for extending its significance beyond the individual, a strategy that works towards the goal of reconstructing curriculum: "For each of us, the more we understand ourselves and can articulate reasons why we are what we are, do what we do, and are headed where we have chosen, the more meaningful our curriculum will be” (Clandinin \& Connelly, 1988, p.11). Tuck and Yang (2012) assert,

Decolonization is accountable to Indigenous sovereignty and futurity. Still, we acknowledge the questions of those wary participants...who want to know what decolonization will require of them. The answers are not fully in view and can't be as long as decolonization remains punctuated by metaphor. (p. 35)

By appropriating decolonial discursive practices within scholarship and projects for social justice that may have objectives that are incommensurate with decolonization, researchers can reduce the ongoing colonial lived reality of Indigenous peoples to a metaphor. Accordingly, we worked to remain unsettled (i.e., the deconstruction component of decolonizing education) in our use of narrative recovery by continually framing the focus on teacher autobiography and experience. This is one approach to curriculum reconfiguration for urban Aboriginal education (i.e., the reconstruction component of decolonizing education), which in Clandinin's and Connelly's (1988) words is the telling of stories with "new insights...with a spirit of 're-vision"' (p. 77).

In the location where the research took place, one local conception of urban Aboriginal education was developed by Anishinaabe Elders and scholars who participated in an Ontario College of Teachers (OCT) conference focussed on preparing an additional qualification (AQ) course for all teachers of Aboriginal students. Anishinaabe knowledge holders drew on the concept of balance, one of the main teachings of the medicine wheel, to call attention to the four interconnected parts of a teacher and associated processes (spiritual/honouring, emotional/understanding, physical/doing, and mental/knowing) that need to be engaged in a balanced manner so teachers can learn to educate the whole child (Flett \& Gardner, 2009).

I drew on this model and complimentary decolonizing (e.g., Battiste, 2012a; Tuck \& Yang, 2012) and Indigenous scholarship (e.g., Archibald 2008; Dion, 2007; Marker, 
2006) as the theoretical and methodological framework that guided this research (Figure 1). It is important to note that I am aware of the pitfalls often encountered in doing crosscultural work that utilizes Indigenous teachings with non-Indigenous participants and/or research. Most importantly, the Anishinaabe teachings within this research were intended for use with both Aboriginal and non-Aboriginal teachers and have been utilized throughout with permission and in continuous consultation with an Anishinaabe scholar and colleague who participated in the development of the original model. I also endeavour to learn from the scholarship of those who have applied decolonizing frames to non-Indigenous individuals (e.g., Biermann, 2011; Regan, 2010; Strong-Wilson, 2007). Through this consultation, I added an additional direction and process, the centre/positioning, to draw attention to the work non-Indigenous teachers need to do in order to position themselves in relation to Indigenous peoples, knowledges, and land.

Narrative inquiry is a way of understanding your own actions and the actions of others, sequencing items and events into a significant whole, and of linking and seeing the effects of actions over a period of time (Clandinin, 2006; Johnson, 2007). To this end, participating teachers were differently involved both independently and with the researcher in several ethnographic narrative inquiry methods, including journal keeping, autobiographical writing, analyzing documents, storytelling, and interviewing. The questions posed in Figure 1 were developed to guide the narrative facilitation and were not explicitly asked of the teacher participants. Rather, they shaped the production of teachers' narratives through the prompts I proposed and activities I facilitated. For example, instead of asking, how they [as a White, Euro-Canadian teachers] describe sources of Indigenous knowledge and Indigenous knowledge holders, I asked teachers to guide me through a "museum walk" of their classroom. Given the nature of the research, participants would typically point out multiple representations and sources of Indigenous knowledge (e.g., samples of Aboriginal students' work, tobacco tie, painting, role-model poster, drum, Aboriginal-themed book). As they described their understanding of Indigenous items and knowledge holders and how they had come to the classroom, they would often comment on their perceived responsibilities to the sources as well as how inclusion impacted the classroom relationships and signalled the legitimacy of Indigenous ways of knowing. Thus, the museum walk was not only a "show and tell" but also a narrative technique to facilitate discussion of how teachers understood Indigenous knowledge and Indigenous knowledge holders.

I modeled a language "close to experience, a language of affect, morality, and esthetics” (Connelly \& Clandinin, 1988, p. 59) informed by my understanding of decolonization by sharing narrative accounts of my involvement in Indigenous education. By doing so, I intended to guide teachers' reflection in a manner that worked towards accounting for the complexity of identity and relationality, representing embodied practices and experiences, and employing a variety of storytelling approaches beyond traditional modes of temporality. In this manner, a narrative approach maintained the two-prong process of deconstruction and reconstruction towards the decolonizing goals of the project. Further, it supported practicing teachers in their continued involvement in Indigenous education in schools that was, first and foremost, responsible to Aboriginal students and community. 
Figure 1. White, Euro-Canadian Teachers’ Positioning, Honouring, Understanding, Doing, and Knowing

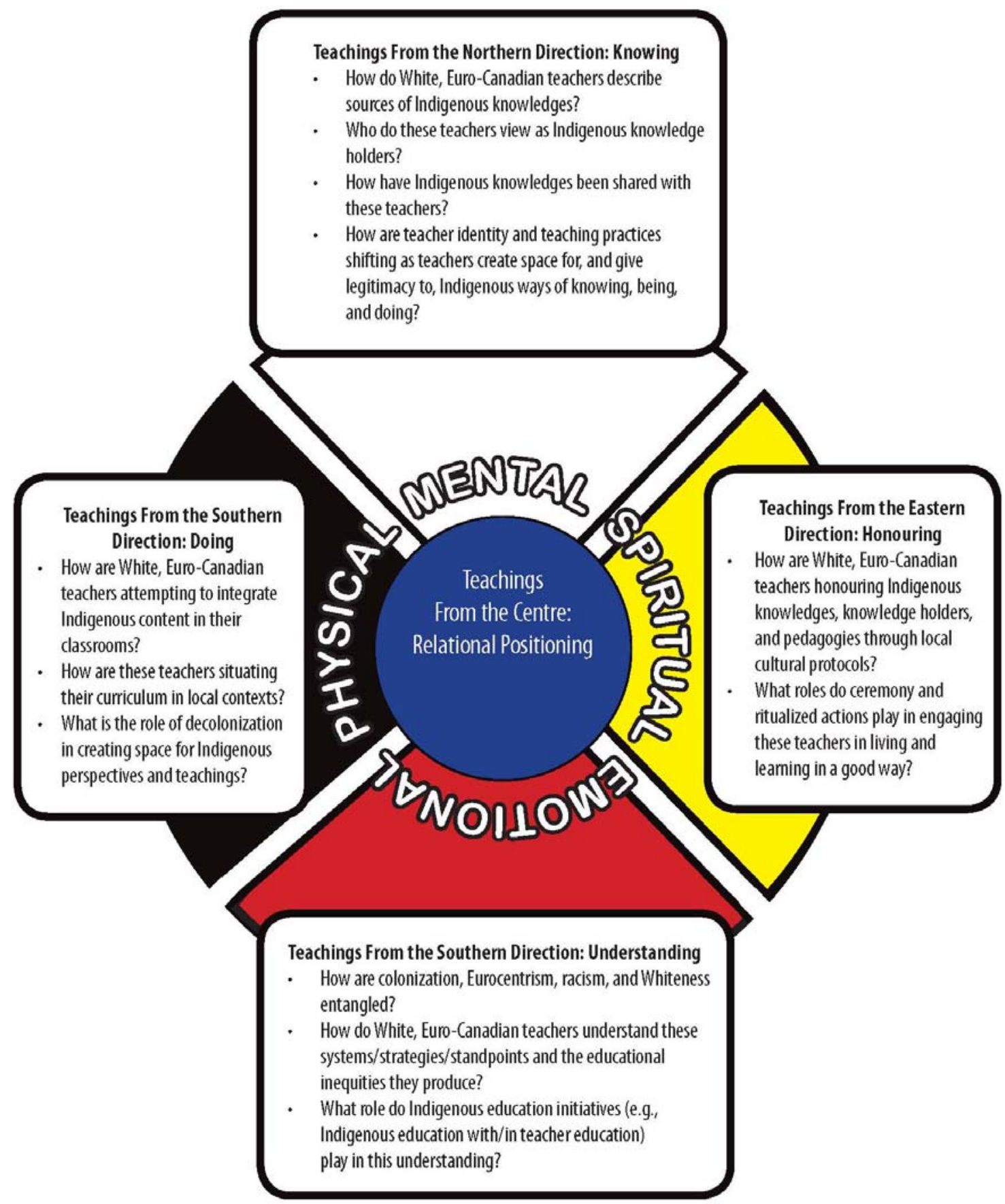

\section{Revisiting Teachings From the Centre: Teachers' Relational Positioning}

My manuscript began with an attempt to locate myself within the relationships that impact how I engage in Indigenous education within and beyond research practices. In 
the interest of brevity, my location will act as the narrative example that anchors a discussion of the decolonizing process of relational positioning. Haig-Brown (2008) argues that too often non-Indigenous peoples leave persisting colonial relations unexamined, which relegates Indigenous thought to a marginalized position. Within education, one effect of this disregard is non-Indigenous teachers who feel "justified" in their limited or negligible participation in Indigenous education initiatives (Madden, Higgins, \& Korteweg, 2013). Teachers who participated in the narrative study challenged this dismissal of one example of neocolonialism by considering their own colonial histories as well as their complicity in contemporary strategies of colonial oppression.

Similar to my introduction to teaching, five out of seven teacher participants started their careers in a Northern community (four on reserve and one off-reserve) where they began to consider the notion of traditional territory and explore the intimate connections between Indigenous peoples, land, knowledges, and language. The remaining two participants were enrolled in graduate studies at the time of the research in an institution where it was common practice to recognize the local First Nation at the commencement of university events. This focus on acknowledging traditional territory helped these teachers to recognize that Aboriginal peoples are the original inhabitants of all land that we now refer to as Canada. Further, it facilitated learning about the established and on-going treaties between sovereign nations and Canada, and the unique constitutional rights of Aboriginal peoples. Teachers often reported taking the initiative to learn about the traditional territories and (when applicable) the associated treaty on which they lived and worked. This inquiry typically extended to the places where they were born and raised, and included tracing their ancestral lineages and histories of settlement.

The teachers investigated their professional identities as well as their involvement in practices that maintained inherited geographical and historical relationships with Indigenous peoples. Teachers began to take note of the ways in which Eurocentrism, the ideology that "Western European cultures are superior and a standard against which other cultures should be judged” (Lewis \& Aikenhead, 2001 p. 53), structured their teacher education programs and pervaded provincial curriculum. They noted how their pedagogical methods often supported the silent curriculum of these systems and they questioned how such approaches and commitments resonated with Aboriginal students and community. In undertaking this inquiry, they often learned alongside Aboriginal knowledge holders and students about conceptions of education that diverged from that which directed their own schooling and professional training (discussed at length in forthcoming sections). James Youngblood Henderson (personal lecture notes from Decolonizing Canadian Education course, 2012) asserted that when false notions of Eurocentric universality and objectivity are challenged, as was the case in learning from Aboriginal knowledges and the modes through which they have traditionally been transmitted, Eurocentrism is revealed as one amongst many orientations to the world. Participants' positioning of themselves as teachers in relationship with Aboriginal peoples and education presented an example of how they directly participate in neocolonial systems. This recognition often appeared as a touchstone, repeatedly revisited as teacher participants explored their participation in the entanglement of colonization, Eurocentrism, racism, and Whiteness within education (see Teachings from the Southern Direction: Doing section). 


\section{Teachings From the Eastern Direction: Honouring}

\section{Katie's Narrative Excerpt}

Last year the students [enrolled in a course focussed on Aboriginal content] wanted to host a powwow in terms of a major project. I was very concerned about doing things wrong. I told the kids "If we are not doing things 100\% right, then we are not doing it." So we had the Elders into the classroom and they talked about the ceremony, what it was for, when it was traditionally held, and the responsibilities of those involved. One student's dad is a powwow organizer. He came in and walked us through the protocols involved in hosting and explained how things-areas for the MC, drums, dancers - should be set up.

When we had an understanding of powwow, two Elders helped us to carry it out. I asked them, "Are we doing it right? Are we missing anything?" I think that they [Elders] appreciated that I asked rather than just forging on ahead with the students and dealing with the consequences of not following traditional protocol later on.

I think it went fabulous. The kids did such an amazing job! I had my own learning journey to go through and the kids knew that too. A lot of those kids had never been on any sort of powwow committee. They had been to a powwow before but never helped to organize. We were learning together and I think that they respected that. (Katie, narrative excerpt, 2010-2011) ${ }^{9}$

Katie's narrative of her experience of facilitating the formation of, and participation in, a powwow committee serves as an exemplar from which to consider some of the processes and challenges of honouring involved in school-based Aboriginal education. Teachers, students, and community members involved in honouring Indigenous knowledges in ceremony, through powwow for example, are entering into mutual exchanges with numerous beings with whom they share the Earth. Drawing on the scholarship of Battiste and Henderson (2000), Castellano (2004) explains the purpose of honouring and the intention of the protocols that guide this dialogue between human, natural, and spirit worlds:

[The phrase "A living, dialogical relationship with the world"] encapsulates the Aboriginal ethic that all aspects of the world we know have life and spirit and that humans have an obligation to learn the rules of relating to the world with respect. We enter into mutual dialogue with the many people and other beings with whom we share the world. When you harvest salmon, you are engaging in a reciprocal relationship in which the spirit of the fish gives sustenance to human beings and humans in turn observe the protocols that demonstrate right relationship. When you seek knowledge from an Elder, you offer tobacco or other appropriate gifts to symbolize that you are accepting the ethical obligations that go with received knowledge. In each case, the exchange confirms a relationship that continues beyond the time and place of the exchange. (p. 104) 
First, Katie arranged to learn about the traditional and contemporary functions of powwow in the area where the ceremony was to be held. She and the students gathered information about the local protocols of powwow (e.g., when and where the powwow could be held, what were the key roles and events of the ceremony, and how the powwow arena was to be prepared and arranged) and their responsibilities as powwow organizers and participants (who should be approached to play key roles in the ceremony, how the community within and beyond the school should be invited, what they should gift in exchange for teachings, and what traditional foods should be served). For the White, Euro-Canadian teacher participants to learn the rules of dialogue (i.e. protocols) that confirm a relationship and its associated responsibilities, support from particular Aboriginal knowledge holders (e.g., powwow organizer) affiliated with the school board was required. Similarly, the teacher participants required frequent guidance throughout the execution of ceremonies and/or ritualized actions (e.g., the offering of tobacco ties, smudging) in order to work towards honouring that was respectful of, and accountable to, relations between human, natural, and spirit worlds. In the board where this research took place, a board-wide commitment to Aboriginal education led to the creation of several permanent positions for Aboriginal knowledge holders within schools and to the availability of funds for honoraria. It is important to note that when systemic accommodations for Indigenous education are not considered, and there is heavy reliance on the knowledges and efforts of Indigenous leaders without appropriate acknowledgement and compensation, this is a form of institutionalized appropriation and neocolonialism (see Newhouse, 2008).

Katie and the other teacher participants expressed great trepidation (e.g., "I was very concerned about doing things wrong") regarding the process of honouring and its spiritual connections. They noted that discussion of spirituality was largely absent from teacher education, except within the boundaries of organized religion. As a result, they often felt they were ill-prepared to include this topic because it exceeded that which was knowable in the canonical sense, despite attempts to frame it as such (e.g. "If we're not doing things 100\% right...”). Positioning themselves as novices engaged in honouring, teacher participants often feared they were misrepresenting and risking appropriation of Indigenous knowledges. Though I risk the collapsing difference and diminishing the importance of ongoing, vibrant engagement in ceremony and ritualized action for regeneration and continuation of traditional knowledges, I suggest it may serve nonIndigenous teachers to consider that their ancestors also honoured humans and otherthan-humans:

Before the triumph of modernity-sealed in Western Europe of the seventeenth century by the advent of the scientific revolution-people lived in constant interaction with a host of beings, powers, and spirits who tricked us, protected us, quarrelled with us, guided us, taught us, punished us, and conversed with us...They taught us that the wealth of the plant beings, the tree beings, the water beings, the soil beings, the mineral beings, was not only ours, was not there for the sole purpose of satisfying our needs. They had their own reason for existing, their own requirements, and their own agency. We needed to ask permission, to share, to give back, and to give thanks. These very gestures made us aware that we were only 
one strand in an immense tapestry that wove the pattern of life on this earth. (Apffel-Marglin, 2011, pp. 3-4)

Similarly, exploration of the ways in which non-Indigenous teachers currently engage and acknowledge the relationships that bind them with others and the land may be reconceptualised as spirituality: honouring found in plain and ordinary experience.

\section{Teachings From the Southern Direction: Understanding}

\section{Jane's Narrative Excerpt}

As a teacher, I need to think critically about who I am and the space I occupy in a room. How do I interact with people? How do I represent myself? What do I appreciate as important? What do I value? How do I reflect those values to people?

I'm specifically thinking about the interactions I have with Aboriginal students, their parents, and their communities as a White person of privilege in a position of power in a social institution. Those interactions occur and if you're not thinking about them critically, then you miss opportunities to form relationships. I hear other teachers say, "The Aboriginal students are just sitting there with their hoods up and they're not talking." It's like, "No! That's not what that's about."

The racism in this city breaks my heart. It's hugely segregated between White and Aboriginal. I want to encourage kids to have a global awareness but I feel like it's a lot easier for people to have empathy for minority and racialized communities in other places because on the ground it's ugly. On the ground, it's getting beat up at the end of the school day. People are able to romanticize those kinds of problems by looking elsewhere and saying, "Oh my God, how could that ever happen?" Well if somebody looked at us, they would say, "How can that happen?” (Jane, narrative excerpt, 2010-2011)

Jane's narrative excerpt gives a glimpse into how White, Euro-Canadian teachers in a Northern community are drawing on their observations of marginalization in schools to foster understanding about the ways in which colonization, Eurocentrism, racism, and Whiteness are entangled. Simply stated, Eurocentrism is intimately connected to Whiteness, which Frankenberg (1993) defines as a set of three linked dimensions that shape White people's lives, a location of structural advantage, of race privilege; it is a standpoint from which White people consider themselves, others, and society overall, and a set of cultural practices that usually go unnamed and unmarked. Western European colonial expansion was achieved, at least in part, through asserting dominance of Eurocentric modes of knowing (e.g., binary oppositions) that enabled and rationalized colonization from the stance of the colonizers (Blaut, 1993; Memmi, 1965/1991). Frankenberg (1993) refers to this notion as "epistemic violence” (see also “cognitive imperialism,” Battiste, 1998) and argues that it concurrently produces racialized ways of conceiving of Indigenous peoples as Other, alongside reformulation of "benevolent" White, European selves. Frankenberg (1993) explains that these associations between 
racist and colonial discourse continue because "the Western self and the non-Western 'other' are co-constructed as discursive products, both of whose 'realness' stand in extremely complex relationships to the production of knowledge, and to the material violence to which 'epistemic violence' is intimately linked” (p. 17).

Jane describes two contrary school-based interactions between Aboriginal peoples and White, Euro-Canadian teachers. The first is marked by the questions she asks of herself that suggest some of the considerations she is taking into account in order to communicate to Aboriginal students and their families that she is an ally in Indigenous education. This demonstrates awareness of the negative associations her position as a teacher with White skin privilege might represent to Aboriginal peoples who are likely affected by the legacies of residential schools ${ }^{10}$ and/or ongoing negative schooling experiences that include racism as well as de-legitimation and exclusion of Indigenous knowledges (Dion, 2007; Friedel, 1999; Kanu, 2002, 2011; Marker, 2006). The second remark noted by Jane, "The Aboriginal students are just sitting there...," suggests that some teachers are reading Aboriginal students as disengaged and uninterested without considering how the centring of European cultures, languages, histories, epistemologies, ${ }^{11}$ and normalizing of Whiteness in schools might exclude those who do not engage from these locations. Donald (2011a, 2011b) argues that ignorance of this sort contributes to the deficit view that Aboriginal students "do not value" education and/or "cannot comprehend" in school. Further, and problematically, ignorance works to reinforce schools as neutral spaces and the status quo as cultureless.

Jane recognized teachers' and students' struggles to see themselves as implicated in "the work of the conquest [that] is being completed here and now" (Kulchyski, 2005, p. 3) and identifies the preference to focus on oppression occurring elsewhere as a strategy of resistance. This sentiment was echoed by several teacher participants who highlighted the importance of being able to access professional development and resources that would support them in revealing and teaching about contemporary Canadian colonial processes (e.g., Eurocentrism) and experiences (e.g., racialized violence and segregation). They argued this training would support them in providing a relevant context from which to examine the integrated systems and strategies of colonization. Consideration of how local and national systems contribute to the oppression of Indigenous peoples, as well as awareness of community interests and methods of resistance and resurgence are vital when engaging in practices that challenge colonial relations of power and dismantle structures of colonization (i.e., decolonizing).

\section{Teachings From the Western Direction: Doing}

\section{Cheryl's Narrative Excerpt}

When I'm looking at pieces of literature, I'm looking for philosophical teachings in the books. One of the novels I did this year focussed on how three characters' participation in circle justice influenced them and their healing. We talked about circle justice from the standpoint of the victim: "If you were a victim of a crime, would you want to participate in a process like circle justice?" A lot of initial responses were, "No. If you commit a crime you deserve to be punished." 
So we did some research on where the idea of circle justice came from, what shaped it, and why it is important. We focused on local teachings about the circle and looked at examples, some in [city where the research took place], of circle justice. Then, we went back to the novel after the main character had been through his process. A lot of the feelings about circle justice had changed. The students better understood what the process was trying to do.

So, it's finding pieces that can bring that type of rich discussion about Aboriginal knowledge and ways. We were able to discuss circle justice in a way that challenged pre-conceived ideas about the process and broadened perspectives. In English class it's easy to do some of that cause you can make some of those humanitarian comparisons and connections. (Cheryl, narrative excerpt, 2010-2011)

This subsection begins with the cautionary note that all teacher participants spoke of the importance of including Aboriginal knowledge, perspectives, and issues for all students in Canada. This commitment was also echoed by the school board who offered several locally developed courses that focussed on Aboriginal content, one of which was the senior English course to which Cheryl refers. My focus on the benefits for Aboriginal students in this manuscript demonstrates my commitment to the communities to which the Aboriginal education initiative was primarily intended to respond to and support. Many stories that were shared by the teacher participants pointed to teachers' reliance on Aboriginal knowledge holders and their use of traditional models for teaching and learning when doing Indigenous education. Because similar excerpts strengthen discussion of two interconnected processes (i.e., honouring and knowing), a selection from Cheryl's narrative has been chosen to ground an exploration of what teachers are doing to integrate Aboriginal content in the absence of a knowledge holder.

Cheryl's use of young adult (YA) literature to learn about Aboriginal teachings and applications of the circle will be framed as an example of culturally responsive pedagogy. Culturally responsive pedagogy has its roots in Ladson-Billings' (1994) culturally relevant pedagogy works toward the central goal of "assist[ing] in the development of a 'relevant black personality' that allows African American students to choose academic excellence yet still identify with African and African American culture” (p. 20) as well as "develop[ing] a critical consciousness through which they challenge the status quo or current social order” (Ladson-Billings, 1995, p. 160). Although LadsonBillings' theories stem from her research with successful teachers of African American children, her work has been extended and modified for use with other cultural groups by using appropriate cultural referents. Within Indigenous education, the term culturally responsive pedagogy is most frequently used. As with Ladson-Billings' culturally relevant pedagogy, Indigenous education includes a focus on both academic and cultural excellence as well as the production of students as critical agents. These characteristics are fostered in localized contexts with attention to particular legal, historical, and linguistic features of groups/peoples/Nations (e.g., Brayboy \& Castagno, 2009; Gay, 2000; Villegas \& Lucas, 2002). 
An example of culturally responsive pedagogy is in Cheryl's extended narrative, when she notes that she frequently draws on literature that features Aboriginal protagonists from a local nation who are often facing the excitements and (often cultural) challenges of adolescence much like the students that she teaches. She notes that Aboriginal students benefit from seeing themselves and their communities reflected in the teaching materials used in classrooms, and are able to participate in perspective taking and relating the literature to their own lives and experiences. Similarly, representations of characteristics of Indigenous worldviews, ${ }^{12}$ what Cheryl refers to as "philosophical teachings," such as the circle and associated teachings and applications (e.g., circle justice) are featured so that students are supported in linking their Aboriginal knowledges with that which is taught in schools.

Cheryl, as well as other teacher participants, spoke about two additional features of using culturally responsive pedagogy for work with Aboriginal students. First, they noted the importance of grounding Aboriginal perspectives and teachings in local contexts by making connections with relevant examples ("We...looked at examples, some in [the city where the research took place], of circle justice"). This grounding was often an important opportunity to enter into a teaching-learning relationship with Aboriginal communities and knowledge holders, which assisted students in making connections founded in culturally specific protocols and teachings. Second, teacher participants offered students the opportunities to compare and contrast Aboriginal content with topics that were typically taught in provincially approved courses (e.g., considering circlejustice alongside topics in Understanding Canadian Law). Through this decolonizing exercise, teachers noted that false notions of Eurocentric universality and objectivity were explored by drawing on Aboriginal examples that challenge a singular understanding/approach. This exercise strengthened students' critical consciousness and ability to assert knowledge and practices that might differ from that which is often normalized within, and beyond, schools. It is important to note that I consider culturally responsive pedagogy for Indigenous students distinct from holistic Indigenous approaches to teaching and learning that are informed by local protocols and intimately connected to language and place (see Archibald, 2008; Young, 2013; Tanaka et al., 2007 for examples), though it may include such approaches. These Indigenous approaches are introduced in the following section.

\section{Teachings From the Northern Direction: Knowing}

\section{Stephanie's Narrative Excerpt}

I arranged the discussion to develop what I thought was a culturally appropriate literacy strategy for a group of junior Aboriginal boys, so I initiated the meeting. I could see the Aboriginal Elders and Aboriginal principal looking surprised as I explained what it was I thought I wanted to happen. The Elders then looked back at the principal and they all started talking. They talked about hunting and trapping. They talked about aunts and uncles and Kookums and Moshums and they talked and they talked and I finally realized what was happening. They were trying to have a discussion about how they were connected to each other. It had nothing 
to do with the topic and I kept thinking, "We have an agenda!," but I sat on my hands and I listened.

It was fascinating to watch and I'm glad I did it because it really helped me to replace a huge piece of my understanding. What I thought was culturally responsive teaching - bringing in the pieces, bringing in the books, bringing in an Elder-isn't enough. There's a whole system, language, thought, and process in place. As teachers, we really have to think about the way structures of power operate in schools: the way we line up, the way we structure schools, what we teach, and the way in which we talk in a classroom. Those things really became important for me, to start paying attention to, because those are the keys.

We can put pictures up of Aboriginal peoples in our classroom and have a book with Aboriginal kids in it, but that's not where the underlying issue is. It's everything we say, our language, our images, the way we conduct ourselves, the way we socialize and teach. These become issues because they are part of a system that's been this way for over a hundred years. We don't even recognize it anymore. (Stephanie, narrative excerpt, 2010-2011)

Stephanie's retelling of her experience of working with Elders acts as a rich site from which to explore the epistemological shifts of White, Euro-Canadian teachers as they create space for, and give legitimacy to, Indigenous ways of knowing, being, and doing. Despite participating in both the board-wide Aboriginal education initiative and a graduate program in education specializing in the same topic, Stephanie appears to overlook the relational positioning that opens the meeting. Her initial viewing of this practice as "off-topic" and impulse to adhere to the agenda may reflect a Eurocentric tendency to value the product over the process, ignoring the Indigenous protocol that often begins the process of learning (Cajete, 1999). Stephanie's declaration that "it [sitting on her hands and listening] really helped me to replace a huge piece of my understanding ... There's a whole system, language, thought, and process in place” suggests that prior to the meeting, she may have been unaware of the depth and complexity of Indigenous knowledge systems. In brief, and noting that Indigenous knowledge "is not a uniform concept across Indigenous peoples" (Battiste \& Henderson, 2000, p. 35), I understand Indigenous knowledges as anchored in land that is situated in diverse and complex geographical, historical, linguistic and political contexts (Cajete, 1994; Marker, 2012). Knowledges are guided by localized protocols and transmitted through traditional approaches to learning, (e.g., storywork, experiential learning, modelling, and ceremony) (Hare, 2011). Indigenous knowledges are holistic, involving the intellectual, spiritual, emotional, and physical realms of an individual in relation with family, community, and nation (Archibald, 2008). Produced from interconnected relationships formed in and through place, and intimately linked to language(s), Indigenous knowledges are dynamic and shaped over time by communication (e.g., ceremony, observing natural processes, adapting survival methods) between human, natural, and spiritual worlds (Dei, 2000, 2011; Kawagley \& Barnhardt, 1998). 
This experience of witnessing relational positioning appears to have precipitated an epiphany of sorts. Stephanie begins to explore how her efforts to include Aboriginal content and perspectives through culturally responsive resources might be strengthened by decolonizing the hidden curriculum in schools (e.g., "the way we line up, the way we structure schools, what we teach, and the way in which we talk in a classroom”). Battiste (2005) argues that a Eurocentric educational framework decontextualizes and parcels Indigenous knowledge into pieces that teachers can "fit" into school subjects and assess according to curricular competencies. This can serve a purpose when done with careful attention; however, more often than not Indigenous knowledge is misrepresented and/or appropriated when the holistic and relational paradigms are ignored. Integrating Indigenous content without attending to Eurocentric educational frames and practices is also problematic as it risks obscuring systemic barriers to integrating Indigenous knowledges in schools (e.g., lack of funding for Elder honoraria) and disregards the processes through which normativity and privilege are established. Battiste (2005) asserts that decolonizing schools involves a critical examination of "what is being taught, who is being excluded and, who is benefitting from public education” (p. 127).

Stephanie's admission that "What I thought was culturally relevant teaching - bringing in the pieces, bringing in the books, bringing in an Elder - isn't enough," suggests that she feels that her teacher training and graduate studies has left her inadequately prepared to support Aboriginal education by drawing on readily available resources (e.g., books, posters, lesson plans). This sentiment was echoed by several teacher participants who shared that they often felt more comfortable and respectful when teaching alongside an Aboriginal knowledge holder. Aikenhead's and Mitchell's (2011) claim that reading about Indigenous knowledges and practices does not necessarily result in understanding may explain teachers' desire to draw on support from knowledge holders. Further, Battiste (2005) clarifies this claim writing, "books and vicarious experiences externalize Indigenous knowledges, but Indigenous knowledge is an intimate relationship" (p. 130). Coming to know involves knowledge transmission through traditional approaches to teaching and learning informed by local protocols such as storytelling and experiential learning on the land (Hare, 2011). This synergy requires time and practice before teaching and learning can occur, as well as a commitment from the learner to engage relationally with the teachings and share them respectfully and responsibly in order for these knowledges and their power to persist (Archibald, 2008). Teachers shared that their confidence in their ability to integrate Aboriginal content and experiment with Indigenous pedagogies increased when they had the opportunity to learn from the modelling of Aboriginal knowledge holders. These findings point to the importance of conceptualizing Indigenous education initiatives that support relationship building with local Indigenous community/ies as well as teacher education that provides opportunities to learn about how to respectfully engage the local protocols of teaching and learning (e.g., acknowledging and honouring the relationships that connect teachers to Indigenous communities and land). Once again, it is vital to ensure policies are in place to support and compensate community members that share their Indigenous knowledges with teachers and students. 


\section{Coming Full Circle: Concluding Thoughts on White, Euro-Canadian Teachers' Decolonizing Processes}

This narrative study of the decolonizing processes of practicing teachers involved in a provincially funded Aboriginal education initiative makes important contributions to the fields of Indigenous education, teacher education, and narrative inquiry. Analysis of narrative excerpts grounded exploration of the five directions/decolonizing processes with which White, Euro-Canadian teachers were engaged in the school board where the research took place: teachings from the centre/positioning, teachings from the east/honouring, teachings from the south/understanding, teachings from the west/doing, and teachings from the north/knowing. Teachings from each direction developed understanding of some of the considerations that need to be taken into account within school-based Indigenous education initiatives. In brief, offering teachers the opportunity to learn about the peoples, hi/stories, and treaty of the traditional territory on which they currently live and work may encourage teacher positioning with respect to their own ancestral lineages and histories of settlement, in relation with Indigenous peoples and land. Training about the purposes, protocols, and processes of honouring is needed so that teachers can learn the local rules of dialogue that confirm a relationship, and may assist in assuaging teachers' consternation that arises from participating in ceremony and ritualized actions. Teachers are drawing on their observations of marginalization in schools to gain understanding about the entanglement of colonization, Eurocentrism, racism, and Whiteness. Professional development and scholarly resources that support exploration of, and teaching about, (teachers' involvement in) local contemporary colonial experiences, strategies, and effects are requested. Modelling of, and classroom resources that support, Indigenous approaches to teaching and learning and culturally relevant teaching for Indigenous students scaffold the doing involved in integrating Indigenous content in schools. Knowing and sharing Indigenous knowledges require collaboration with Indigenous Elders and knowledge holders who utilize Indigenous pedagogies informed by local protocols for knowledge transmission. Systemic supports such as funding for honoraria, bilingual community liaisons, flexible temporal and spatial scheduling, and teacher education focussed on the local protocols of teaching and learning support longstanding, respectful relationships with Indigenous communities.

After a careful review of the body of literature for this study, it is apparent that attention to race and racialized locations (including Whiteness) is often diminished or absent from studies that focus on university- or school-based Aboriginal education. This study of teachers who work in an urban location where racialized/White relations map almost analogously onto Aboriginal/non-Aboriginal relations points to the inadequacy of teacher education or professional development that has Aboriginal/Indigenous education as its central focus and does not consider the role of race and racism in teachers' engagement. Much more attention to the shared spaces between and among Indigenous and race-based theories are needed to analyze the ways in which race differently contributes to the production of privilege in the ongoing context of settler colonialism. Incorporating theories that consider race could aid in generating greater support for and participation within Aboriginal education, in resisting reproduction of neo-colonial identities such as "White rescuer," and in developing more fulsome and nuanced decolonizing theories that consider, at least, race, ethnicity, and gender. 
Lastly, the use of narrative inquiry towards decolonizing goals extends the scope of this methodology as the purpose of reconfiguring the past and re-visioning the future is embedded within a locally specific school-based Aboriginal education initiative. The two-prong process of deconstructing and reconstructing was incorporated into research methods by using a variety of narrative techniques, first, to examine autobiography and experiences in relation to neocolonial strategies and processes, particularly within the context of schools where ignorance is used to exploit and justify the marginalization of Aboriginal peoples and the theft of Aboriginal lands and resources, and second, to revision, re-purpose, and re-humanize schools (Wolf, 2012, p. 47) through honouring localized education priorities as outlined by the local Aboriginal community. In this manner, narrative inquiry was richly theorized. Drawing on decolonizing, Indigenous education, and Whiteness scholarship supported the execution of particular research methods in working towards associated transformative goals. 


\section{References}

Aboriginal Affairs and Northern Development Canada (AANDC). (2010). Canada and the Caldwell First Nation reach major milestone in claim settlement process. Retrieved from: http://www.aadnc-aandc.gc.ca/eng/1100100016076

Aikenhead, G., \& Michell, H. (2011). Bridging cultures: Indigenous and scientific ways of knowing nature. Don Mills, ON: Pearson Canada Inc.

Apffel-Marglin, F. (2011). Subversive spiritualties: How rituals enact the world. Oxford, UK: Oxford University Press.

Archibald, J. (2008). Indigenous storywork: Educating the heart, mind, body, and spirit. Vancouver, BC: UBC Press.

Battiste, M. (1998). Enabling the autumn seed: Toward a decolonized approach to Aboriginal knowledge, language, and education. Canadian Journal of Native Education, 22(1), 16- 27.

Battiste, M. (2005). You can't be the global doctor if you're the colonial disease. In P. Tripp \& L. Muzzin (Eds.), Teaching as activism: Equity meets environmentalism (pp. 121-133). Montreal, QC: McGill-Queen’s University Press.

Battiste, M. (2012a). Aboriginal education. Unpublished manuscript, Department of Educational Foundations, University of Saskatchewan, SK, Canada.

Battiste, M. (2012b). Bringing Aboriginal education into conventional education: Nourishing the learning spirit. Paper presentation at 2012 Canadian Society for the Study of Education (CSSE) Annual Meeting, Waterloo, ON.

Battiste, M., \& Henderson, J. S. Y. (2000). Protecting Indigenous knowledge and heritage, a global challenge. Saskatoon, SK: Purich Publishing Ltd.

Belczewski, A. (2009). Decolonizing science education and the science teacher: A White teacher's perspective. Canadian Journal of Science, Mathematics and Technology Education, 9(3), 191-202.

Biermann, S. (2011). Knowledge, power and decolonization: Implications for nonIndigenous scholars, researchers and educators. In G. J. S. Dei (Ed.), Indigenous philosophies and critical education: A reader (pp. 386-398). New York, NY: Peter Lang Publishing, Inc.

Bishop, R., Berryman, M., Cavanaugh, T., \& Teddy, L. (2009). Te Kotahitanga: Addressing educational disparities facing Maori students in New Zealand. Teaching and Teacher Education, 25, 734-742.

Blaut, J. M. (1993). The colonizer's model of the world: Geographical diffusionism and Eurocentric history. New York, NY: Guilford Press.

Brayboy, B., \& Castagno, A. (2009). Self-determination through self-education: Culturally responsive schooling for Indigenous students in the USA, Teaching Education, 20(1), and 31- 53. 
Cajete, G. (1994). Look to the mountain: An ecology of Indigenous education. Skyland, NC: Kivaki Press.

Cajete, G. A. (1999). Igniting the sparkle: An Indigenous science education model. Durango, Mexico: Kivaki Press.

Castellano, M. B. (2004). Ethics of Aboriginal research. Journal of Aboriginal Health, 1(1) 98-113. Retrieve from http://www.naho.ca/jah/english/jah01_01/journal_p98-114.pdf

Chrisjohn, R. D., \& Young, S. (2006). The circle game: Shadows and substance in the Indian residential school experience in Canada. Penticton, BC: Theytus Books.

Clandinin, D. J. (2006). Narrative inquiry: A methodology for studying lived experience. Research Studies in Music Education, 58(1), 21-35.

Clandinin, D. J., \& Connelly, M. (1988). Teachers as curriculum planners. Narratives of experience. New York, NY: Teachers College Press.

Dei, G. J. S. (2000). Indigenous knowledges in contexts: Multiple readings of our world. Toronto, ON: University of Toronto Press.

Dei, G. J. S. (2011). Revisiting the question of the 'Indigenous'. In Dei, G. J. S. (Ed.), Indigenous philosophies and critical education: A reader (pp. 21-33). New York, NY: Peter Lang Publishing, Inc.

den Heyer, K. (2009). Sticky points: Teacher educators re-examine their practice in light of a new Alberta social studies program and its inclusion of Aboriginal perspectives. Teaching Education, 20(4), 343-355.

Dion, S. D. (2007) Disrupting molded images: Identities, responsibilities and relationships — teachers and Indigenous subject material. Teaching Education, 18(4), 329-342. doi: 10.1080/10476210701687625

Dion, S. (2009). Braiding histories: Learning from Aboriginal peoples’ experiences and perspectives. Vancouver, BC: UBC Press.

Donald, D. (2011a). Indigenous Métissage: A decolonizing research sensibility. International Journal of Qualitative Studies in Education, 25(5), 535-555. doi: 10.1080/09518398.2011.554449

Donald, D. (2011b). Big thinking-On what terms can we speak? Aboriginal-Canadian relations as an educational priority. Federation for Humanities \& Social Sciences. Retrieved from http://vimeo.com/21534649

Flett, J., \& Gardner, E. (2010). Nourishing the teaching spirit. Proceedings from Conversation Circles to Support the Development of Additional Qualification Guidelines for Teaching First Nations Students, ON.

Frankenberg, R. (1993). White women, race matters: The social construction of Whiteness. Minneapolis, MN: University of Minnesota Press. 
Friedel, T. L. (1999). The role of Aboriginal parents in public education: Barriers to change in an urban setting. Canadian Journal of Native Education, 23(2), 139225.

Gay, G. (2000). Culturally responsive teaching: Theory, research and practice. New York, NY: Teachers College Press.

Gray, R. R. R. (2011). Visualizing pedagogy and power with urban Native youth: Exposing the legacy of the Indian residential school system. Canadian Journal of Native Education, 34(1), 9-27.

Gregg, A. R. (2012). Tecumseh’s ghost. Retrieved from http://allangregg.com/tecumseh/

Haig-Brown, C. (2008). Taking Indigenous thought seriously: A rant on globalization with some cautionary notes. Journal of the Canadian Association for Curriculum Studies, 6(2), 8-24. Retrieve from http://bit.ly/1pRggPB

Hare, J. (2011). Indigenous knowledge in education. In O. Dickason \& D. Long (Eds.), Visions of the heart ( $3^{\text {rd }}$ ed., pp. 90-112). Don Mills, ON: Oxford University Press.

Higgins, M., Madden, B., \& Korteweg, L. (2013). Witnessing (halted) deconstruction: 'White teachers' 'perfect stranger' position within urban Indigenous education. Race Ethnicity and Education, Online First. Retrieved from http://dx.doi.org/10.1080/13613324.2012.759932

Hookimaw-Witt, J. (1998). Any changes since residential schools? Canadian Journal of Native Education, 22(2), 159-170.

Iseke-Barnes, J. (2008). Pedagogies for decolonizing. Canadian Journal of Native Education, 31(1), 123-148.

Johnson, A. S. (2007). An ethics of access: Using life history to trace preservice teachers' initial viewpoints on teaching for equality. Journal of Teacher Education, 58(4), 299-314.

Kanu, Y. (2002). In their own voices: First Nations students identify some cultural mediators of their learning in the formal school system. Alberta Journal of Educational Research, 48(2), 98-119.

Kanu, Y. (2011). Integrating Aboriginal perspectives into the school curriculum. Toronto, ON: University of Toronto Press.

Kawagly, O., \& Barnhardt, R. (1998). Education indigenous to place: Western science mee Native reality. Fairbanks, AK: Alaska Native Knowledge Network.

Kirkness, V. (1999). Aboriginal education in Canada: A retrospective and a prospective. Journal of American Indian Education, 39(1), 14-30.

Kulchyski, P. (2005). Like the sound of a drum: Aboriginal cultural politics in Denedeh and Nunavut. Winnipeg, MB: University of Manitoba Press. 
Ladson-Billings, G. (1994). The dreamkeepers: Successful teachers of African American children. San Francisco, CA: Jossey-Bass.

Ladson-Billings, G. (1995). But that's just good teaching! The case for culturally relevant pedagogy. Retrieved from http://www.outdoorfoundation.org/pdf/CulturallyRelevantPedagogy.pdf

Lewis, B., \& Aikenhead, G. (2001). Introduction: Shifting perspectives from universalism to cross-culturalism. Science Education, 85(1), 3-5. doi: 10.1002/1098-237X(200101)85:1<3::AID-SCE2>3.0.CO;2-2

Little Bear, L., (2009, July). Naturalizing Indigenous knowledge: Synthesis paper. Paper prepared for Canadian Council on Learning's Aboriginal Learning. Issued by the Aboriginal Learning Knowledge Centre, University of Saskatchewan, Saskatoon, SK. Retrieved from http://www.ccl-cca.ca/pdfs/ablkc/naturalizeIndigenous_en.pdf

Madden, B., Higgins, M., \& Korteweg, L. (2013). “Role models can’t just be on posters”: $\mathrm{Re} /$ membering barriers to Indigenous community engagement. Canadian Journal of Education, 36(2), 212 - 247.

Marker, M. (2004). Theories and disciplines as sites of struggle: The reproduction of colonial dominance through the controlling of knowledge in the academy. Canadian Journal of Native Education, 28(1/2), 102- 110.

Marker, M. (2006). After the Makah whale hunt: Indigenous knowledge and limits to multicultural discourse. Urban Education, 41(5), 482-505.

Marker, M. (2012). Teaching history from an Indigenous perspective: Four winding paths up the mountain. In P. Clark (Ed.), New possibilities for the past. Shaping history education in Canada (pp. 97-112). Vancouver, BC: UBC Press.

Memmi, A. (1991) The colonizer and the colonized. (H. Greenfeld, Trans.). Boston, MA: Beacon Press.

Newhouse, D. (2008). Ganigonhi:oh: The good mind meets the academy. Canadian Journal of Native Education, 31(1), 184-197.

Oberg, A., Blades, D., \& Thom, J. S. (2007). Untying a dreamcatcher: Coming to understand possibilities for teaching students of Aboriginal inheritance. Educational Studies (American Educational Studies Association), 42(2), 111-139.

Phillips, J., \& Whatman, S. (2007). Decolonising preservice teacher education: Reform at many cultural interfaces. Paper presented at the World of Educational Quality: 2007 AERA Annual Meeting. Chicago, United States of America (pp. 194-194). Retrieved from http://www.eprints.qut.edu.au/7333/1/7333.pdf

Regan, P. (2010). Unsettling the settler within: Indian residential schools, truth telling, and reconciliation in Canada. Vancouver, BC: UBC Press. 
Sanford, K., Williams, L., Hopper, T., \& McGregor, C. (2012). Indigenous principles informing teacher education: What we have learned. in education, 18(2), Retrieved from http://ineducation.ca/ineducation/article/view/61/548

Statistics Canada. (2006). Aboriginal peoples. Retrieved from http://www12.statcan.gc.ca/census-recensement/2006/rt-td/ap-pa-eng.cfm

Strong-Wilson, T. (2007). Moving horizons: Exploring the role of stories in decolonizing the literacy education of White teachers. International Education, 37(1), 114-131.

Tanaka, M., Williams, L., Benoit, Y. J., Duggan, R. K., Moir, L., \& Scarrow, J. C. (2007). Transforming pedagogies: Pre-service reflections on learning and teaching in an Indigenous world. Teacher Development, 11(1), 99-109.

Truth and Reconciliation Committee (TRC). (2012). Canada, Aboriginal peoples, and residential schools: They came for the children. Winnipeg, MB: Truth and Reconciliation Commission of Canada.

Tuck, E., \& Yang, W. (2012). Decolonization is not a metaphor. Decolonization: Indigeneity, Education \& Society, 1(1), 1-40.

Tupper, J. (2011). Disrupting ignorance and settler identities: The challenges of preparing beginning teachers for treaty education. in education, 17(3), Retrieve from http://ineducation.ca/ineducation/article/view/71/415

Villegas, A. M., \& Lucas, T. (2002). Preparing culturally responsive teachers: Rethinking the curriculum. Journal of Teacher Education, 53(1), 20-32. doi: $10.1177 / 0022487102053001003$

Wolf, S. J. (2012). Critical citizenship, popular theatre, and the social imagination of preservice teachers. In R. Mitchell \& S. Moore (Eds.). Politics, participation and power relations:Transdisciplinary approaches to critical citizenship in the classroom and community (pp. 35-49). Rotterdam, NL: Sense Publications.

Young, A. (2013). Ceremony principles \& pedagogy: PowerPoint. Teaching for Indigenous Education. Retrieved from http://www.kaltura.com/index.php/extwidget/openGraph/wid/0_xae4cylp

\section{Endnotes}

${ }^{1}$ As this manuscript draws on local as well as global Indigenous scholarship, I often utilize the term Indigenous when discussing decolonization and education initiatives. Within Canada, Indigenous peoples are often referred to as Aboriginal and this term includes First Nations, Inuit, and Métis peoples. To reflect localized specificity and counter the tendency to collapse difference, Aboriginal and/or Anishinaabe are also utilized when referring specifically to the research. This discursive practice reflects the artifacts (e.g., policy and curricular documents) produced by the school board where the research took place and the words utilized by research participants. 
2 The school board where the research took place describes Anishinaabe as an Aboriginal confederacy of three nations: Ojibway (Faith Keepers), Odawa (Warriors and Traders), and Potawatomi (Fire Keepers).

${ }^{3}$ I do not mean to imply a sense of threat or danger; rather, I intend to signal the oftenoverlooked presence of Indigenous-non-Indigenous connections.

${ }^{4}$ Michif is the language of the Métis people of Canada.

${ }^{5}$ Mémé is an informal French term that refers to grand-mère, which is French for grandmother.

${ }^{6}$ This study is not referenced in an attempt to protect teacher participants' anonymity.

${ }^{7}$ In the city where the research took place, official census data states that $8 \%$ of the total population identified as Aboriginal. This proportion is likely larger among students because Aboriginal peoples are the fastest growing demographic in Canada with $48 \%$ of the population under the age of 25 years old (compared to 31\% for the non-Aboriginal population) (Statistics Canada, 2006). Likely, the official numbers under-represent the Aboriginal presence in the research context as a notable transient population exists that includes Aboriginal secondary students that board in the urban centre for the duration of the school year. According to policy documents, Aboriginal students in the school board studied identify as Anishinaabe, Oji-Cree, Muskegowuk (Woodland) Cree, and/or Métis. To recognize the traditional territory and peoples on which the school board now exists, Anishinaabe knowledges as well as associated initiatives and collaborations are often centred in policy and curricular documents.

${ }^{8}$ Approximately 70 practicing teachers participated in at least one focus group with over half attending two or more sessions.

${ }^{9}$ These narrative excerpts were produced over eight months in collaboration with the research participants. In general, this process involved conducting and transcribing participant interviews and additional activities. Transcripts were reviewed by teacher participants and their edits and concerns incorporated into their narratives, with the review process becoming part of the data. Particular narrative excerpts have been selected and reworked with participants for research dissemination. I view the generation of narrative excerpts with attention to deconstructing and reconstructing as one approach to decolonizing Clandinin and Connelly's (1988) narrative inquiry.

${ }^{10}$ Residential schools resulted in the neglect, abuse, and death of Aboriginal students as well as cultural, historical, and linguistic erasures. As a whole, the effects of the weakening of Aboriginal peoples through the 100+ years of residential schools can still be seen today. Attributed to these early schooling systems are cultural conflict; poor selfconcept; poverty and underdevelopment; disproportionate levels of incarceration, substance abuse, and sickness; and death from preventable illness (Chrisjohn \& Young, 2006; Gray, 2011; Kirkness, 1999; TRC, 2012).

${ }^{11}$ It is important to note that a Eurocentric framework for education can also challenge Indigenous notions of holism and decontextualize Indigenous knowledges through 
organization by disciplinary subjects and a focus on curricular competencies (Archibald, 2008; Hookimaw-Witt, 1998; Marker, 2004).

${ }^{12}$ I wish to highlight my understanding of the important difference between Western worldviews that often focus on knowledge acquisition, and the process-based interconnections between Indigenous coming-to-knowing, coming-to-being, and comingto-doing (Castellano, 2004) or epistemology, ontology, and axiology that often anchor Indigenous worldviews. 